\title{
Nursing of a child with wound infection and bowel evisceration following ileostomy: a case report
}

\author{
Sha Li \\ Department of Neonatal Surgery, Guangzhou Women and Children's Medical Center, Guangzhou, China \\ Correspondence to: Sha Li. Bachelor of Science, Nurse-in-Charge, Department of Neonatal Surgery, Guangzhou Women's and Children's Medical \\ Center, Guangzhou, China. Email: lisha860507@163.com.
}

\begin{abstract}
Children after ileostomy, due to excreta characteristics and improper nursing and other reasons, causes waste collection difficulties. Leakage of intestinal waste leads to wound infection. Wound infections further increase the difficulty of collecting excreta. Alternate circulation exacerbates wound infection. The wound was seriously infected until the whole layer split and the intestinal tract was exposed. Even endangering life. Thus, in these cases, it is particularly important to effectively collect bowel contents at the intestinal stoma, promote wound healing, and save lives. This article summarizes our experience in the nursing of a pediatric patient with wound infection and bowel evisceration following ileostomy. Comprehensive assessment of children, setting care targets, implementing holistic care. For local situations, the ostomy devices and supplies were appropriately used to enable the effective collection of liquid stool. Guided by the theory of wound bed preparation and wet healing theory, a self-made simple negativepressure device and modern wound dressings were used in different stages of wound development. In order to effectively manage wound exudate, remove necrotic tissue and promote granulation growth. Finally, promoting wound healing. Through the above nursing methods, oral waste can be collected effectively. The open bowel is well protected. The wounds were smoothly healed, and the patient was discharged on day 32 .
\end{abstract}

Keywords: Ileostomy; wound infection; wound bed preparation; negative-pressure drainage; nursing

Submitted Mar 19, 2020. Accepted for publication Jul 14, 2020.

doi: 10.21037/apm-20-1189

View this article at: http://dx.doi.org/10.21037/apm-20-1189

\section{Introduction}

Peristomal skin complications are common in children. In particular, the incidence of peristomal skin injury has been reported to reach $26.90-56.36 \%$ following ileostomy (1-3), which is mainly due to the excretory characteristics of the stomas (4). Skin damage makes it difficult to place the ostomy bag, leading to difficulty in collecting liquid stool. Since children have smaller abdominal areas than adults, the leaked fecal discharge can easily contaminate the wound as a result of the short distance between the wound and the stoma, resulting in wound infection and even organ evisceration (5). Even worse, the large amounts of wound exudate affects the sticking of ostomy bags, leading to leakage of fecal discharge onto the wound surface, forming a vicious cycle and making the nursing of such cases extremely difficult (6).

There was a similar report (Application of modified wound vacuum suction in nursing care of patients with wound splitting and infection after ileostomy. But This report mainly describes the application of the original set of wound suction devices to adult wounds to cracked wounds after improvement. It is aimed at adults rather than children.

In August 2018, a pediatric patient with severe peristomal wound infection and bowel evisceration was admitted to our hospital. Based on the theory of wound bed preparation (7), for the first time, we used a self-made simple negative-pressure device to drain and collect the wound exudate and fecal discharge and used an ostomy 


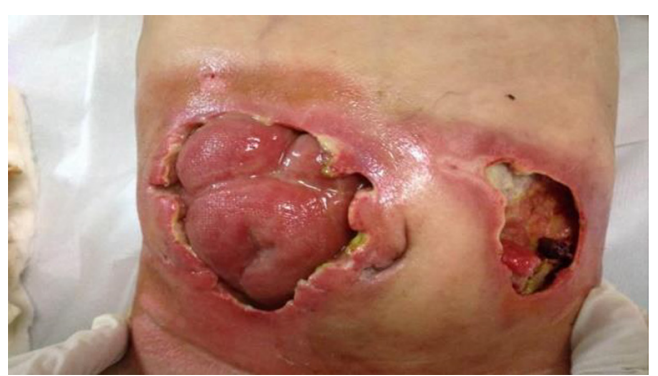

Figure 1 Wounds and stoma at admission.

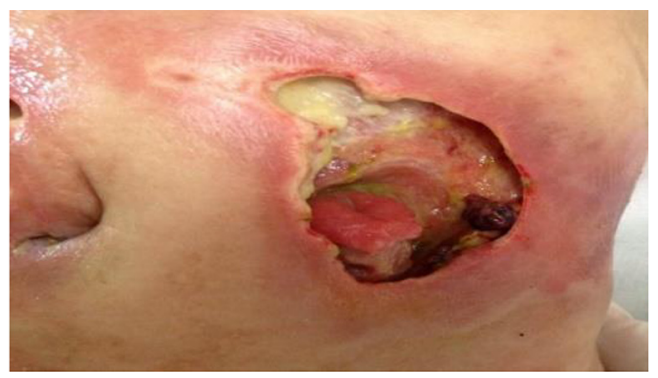

Figure 2 A wound (sized $7 \mathrm{~cm} \times 6.5 \mathrm{~cm}$ ) located at the lower left quadrant of the abdomen.

bag and other supplies to collect liquid stool, so as to reduce the contamination of the wound caused by fecal discharge. Meanwhile, modern wound dressings were applied for the wounds at different stages and for irritant dermatitis around the stoma, so as to promote the healing of the wound and treat the irritant dermatitis around the stoma. The results are described below.

The following case was presented in accordance with the CARE reporting checklist (available at http://dx.doi. org/10.21037/apm-20-1189).

\section{Case presentation}

\section{General data}

The male patient was 1 year and 10 months old, weighing $10.1 \mathrm{~kg}$. He underwent ileostomy due to neonatal necrotizing enterocolitis and intestinal perforation in another hospital in 2017 , and the specific operative procedure and timing were unknown. Due to financial difficulties, the patient was discharged on the third postoperative day upon the request of his parents. After discharge, the child continued to have moderate fever, with a peak temperature of $38.9^{\circ} \mathrm{C}$. His family rejected the use of any medication. No further treatment was applied to the stoma and wound. The family complained that the surgical wound gradually became flushed and cracked, leading to bowel evisceration, although the specific timing was unknown. On August 19, 2018, the patient was admitted to the Department of General Surgery of our hospital via the Emergency Room due to "abdominal wound infection and bowel evisceration". All procedures performed in studies involving human participants were in accordance with the ethical standards of the institutional and/or national research committee(s) and with the Helsinki Declaration (as revised in 2013). Informed consent was obtained from the parents for the use of photos and information in this article.

\section{Nursing assessment at admission}

\section{Systemic assessment}

Physical examination: The axillary temperature was $38.9^{\circ} \mathrm{C}$, and the other vital signs were stable. After regular fasting, no gastric juice was drained after gastrointestinal decompression. The abdomen was slightly swollen but remained soft. The patient was conscious at admission, with general reactions. He had dry skin and moderate malnutrition. His Face, Legs, Activity, Cry, Consolability (FLACC) pain score was 5 points.

Laboratory tests: C-reactive protein (CRP) was 35.4, white blood cell (WBC) count was $22 \times 10^{9}$, neutrophil percentage was $74 \%$, and hemoglobin was $82 \mathrm{~g} / \mathrm{dL}$.

\section{Local assessment}

Wounds and stoma assessment: the wounds and stoma were thoroughly cleaned with saline at admission (Figure 1) (8).

One wound (sized $7 \mathrm{~cm} \times 6.5 \mathrm{~cm}$ ) was located at the lower left quadrant of the abdomen (Figure 2). About $75 \%$ of its base tissue was red, and $25 \%$ was yellow. A large volume of feces-odored exudate was visible. The skin around the wound was flushed and swollen. There was $2 \mathrm{~cm}$ of wound undermining from 12 to 3 o'clock which became connected with the right-sided wound at 9 o'clock. A stoma was found in the wound. The opening of the bowel was lower than the skin around the wound, and much yellow liquid stool was discharged via the opening. The blood supply of the bowel was good.

Another wound (sized $9 \mathrm{~cm} \times 10 \mathrm{~cm}$ ) was located at the lower right quadrant of the abdomen (Figure 3). Up to $100 \%$ of its base tissue was red, and yellow-green feces were seen around the base. A large volume of feces-odored 


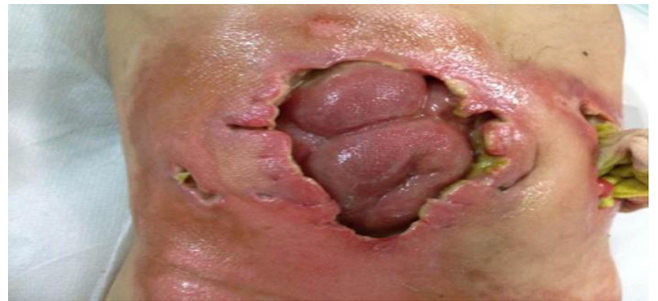

Figure 3 A wound located at the lower right quadrant of the abdomen at admission.

exudate was visible. The skin around the wound was flushed and swollen. The wound was connected with the left-sided wound at 3 o'clock. Bowel evisceration occurred. The bowel was red in color, with good blood supply, and no opening was found.

\section{Nursing diagnosis}

\section{Fever}

It was suspected that the patient's fever might have been a result of the elevated WBC count following wound infection.

Treatment targets: the treatment targets were for the body temperature to return to normal and the WBC count to return to normal within 1 week. C-reactive protein (CRP) reduce from 35.4 , to below 10 .

\section{Malnutrition}

Use WHO BMI Chart for Girls 0-5 years, the child is severely malnourished. The reason is too much consumption. Treatment targets: the treatment targets were for the body weight of the child to increases to $12 \mathrm{~kg}$, and to achieve a normal nutrition score.

\section{Impaired skin integrity}

Impaired skin integrity was related to the wound infection near the stoma and to the bowel evisceration.

Treatment targets: the treatment targets were to protect the exposed intestinal canal, collect wound exudate, and make the bowel at the stoma become protruded, which would facilitate the effective collection of liquid stool and reduce wound contamination. We also wanted to control the wound infection, promote wound healing, and prepare the wound bed for the second operation.

\section{Pain}

Pain was associated with the impaired skin integrity.

Treatment targets: the treatment target was to lower the FLACC pain score to 0 .

\section{Lack of nursing knowledge}

Intervention targets: the intervention target was to increase the parents' awareness of the value and targets of the treatments so that they could actively cooperate with the medical staff during the treatment.

\section{Nursing measures}

\section{Fever}

Body temperature was measured 6 per day on a daily basis and symptomatic treatment was offered. Physical cooling was performed when the body temperature was below $38.5^{\circ} \mathrm{C}$; fever above $38.5^{\circ} \mathrm{C}$ was reported to a doctor in timely fashion and usually treated with drugs. The ambient temperature was kept stable. The parents were instructed to immediately identify and report early symptoms and signs associated with the abnormal body temperature and to cooperate with basic nursing; for instance, they were instructed to immediately change the wet clothes of the child in order to strengthen the basic cleanliness of the body. The results of laboratory tests were regularly monitored. Antibiotics were used as ordered by the physician.

\section{Nutrition management}

The nurses regularly assessed the nutritional status of the child and reported any abnormal findings to the doctor. The doctor adjusted the nutritional status of the child by giving parenteral nutrition. Special milk powder was used after consulting a dietitian.

\section{Pain management}

The child's pain was regularly assessed by using the FLACC scale. Physical therapy, psychological therapy, or drug therapy was offered according to the assessment result. The assessment was performed genially, for which the parents were invited to join, which helped the child to talk about his feelings.

\section{Nursing of the wounds and stoma} Nursing of the left-sided wound

Nursing technique: the wound was thoroughly cleaned 


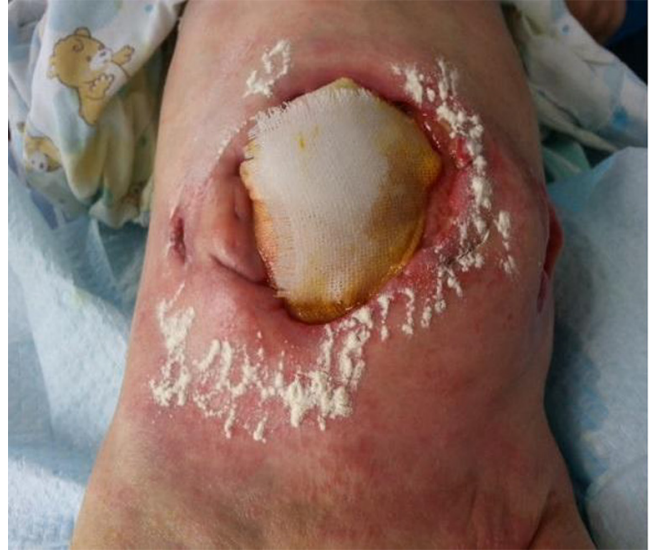

Figure 4 The exposed bowel is covered by using petroleum jelly.

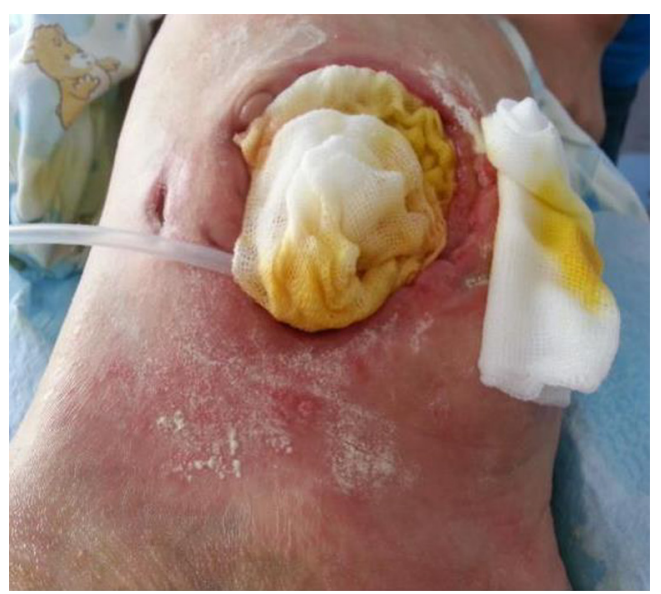

Figure 5 Placement of the precut 8 Fr gastric tube.

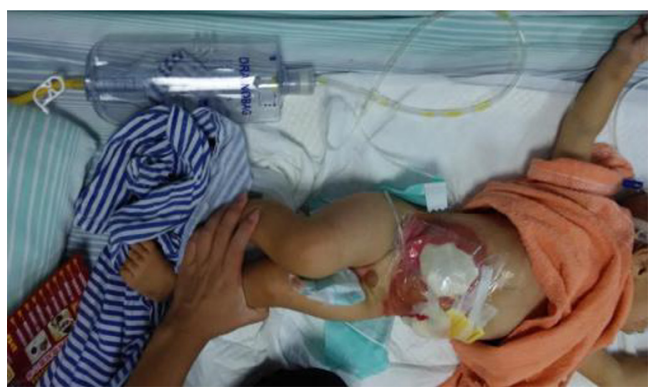

Figure 6 Connection with a disposable negative-pressure drainage bag after the application of a 3MTM transparent applicator.

with saline and then wiped dry with sterile gauze. The exposed bowel was gently covered by using petroleum jelly. Multiple holes were made on the side wall of an Fr8 silicone gastric tube according to the wound size by using a pair of sterile scissors until reaching the mark of $15 \mathrm{~cm}$. Petroleum jelly was used to cover the perforated part of the gastric tube, and then the tube was put into the wound; direct contact of the tube with the base of the wound was avoided, so as to prevent blockage. Stoma-protecting powder was applied onto the skin around the wound, which was then covered with $3 \mathrm{M}^{\mathrm{TM}}$ liquid dressing. The entire wound surface was covered with sterile gauze and then sealed with $3 \mathrm{M}^{\mathrm{TM}}$ transparent applicator. It was then connected with a disposable negative-pressure drainage bag (model w-II; Kang Li Medical New Technology Co, Ltd, Guangdong, China). After the negative-pressure drainage bag was squeezed with both hands, it was observed that the transparent film collapsed on the wound surface, indicating the device was airtight (9).

Vacuum-assisted closure (VAC) of the wound was initially developed by the German surgeon, Fleischmannl, and introduced to China by Professor Huade Qiu. It has the following advantages: (I) it enables adequate and thorough drainage; (II) it changes the open wound to a closed environment, lowering the risk of infection; (III) it maintains a continuous negative-pressure status to stimulate capillary regeneration and promote the growth of granulation tissue, thus providing favorable conditions for the success of the secondary flap repair or skin graft surgery (10). After continuous negative-pressure drainage for 3 days, the covering materials were opened to observe the wound and evaluate whether retreatment was needed (Figures 4-6).

Outcomes: the timing of gauze changing was decided according to the airtightness of the negative-pressure device, the amount of drainage, and the shape of the gauze under the transparent dressing. By September 5, the wound had gradually shrunk to $4.5 \mathrm{~cm} \times 3 \mathrm{~cm}$, and the amount of exudate and liquid feces collected decreased from $60 \mathrm{~mL}$ (24 hours after the first dressing change) to a small amount (the gauzes were then changed every 24 hours) (11). Negative-pressure drainage was stopped, and the exudate had no odor. The redness and swelling of the skin around the wound subsided, although a small amount of scattered rashes were still visible. The base of the wound was ruddy, and the exposed bowel had intact mucosa (Figures 7,8).

\section{Nursing of the right-sided wound and stoma}

Nursing technique-wound infection stage: the wound was thoroughly cleaned with saline and then wiped dry with sterile gauze. The hydrofiber dressing with silver was cut into pieces with sterile scissors according to the size of the 

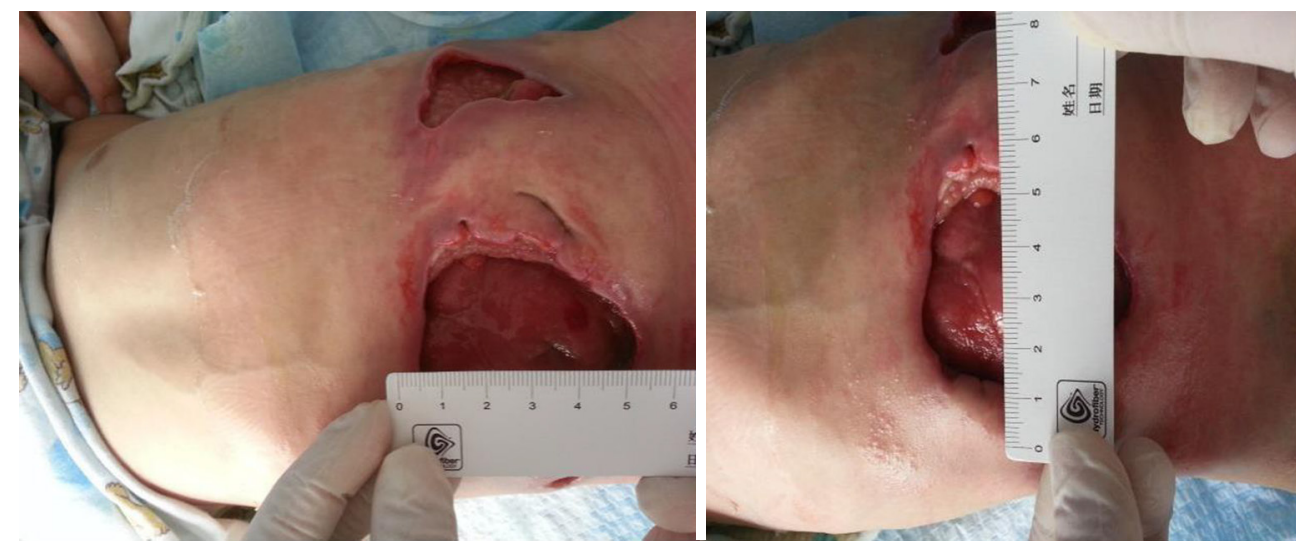

Figure 7 The left-sided wound on August 28.
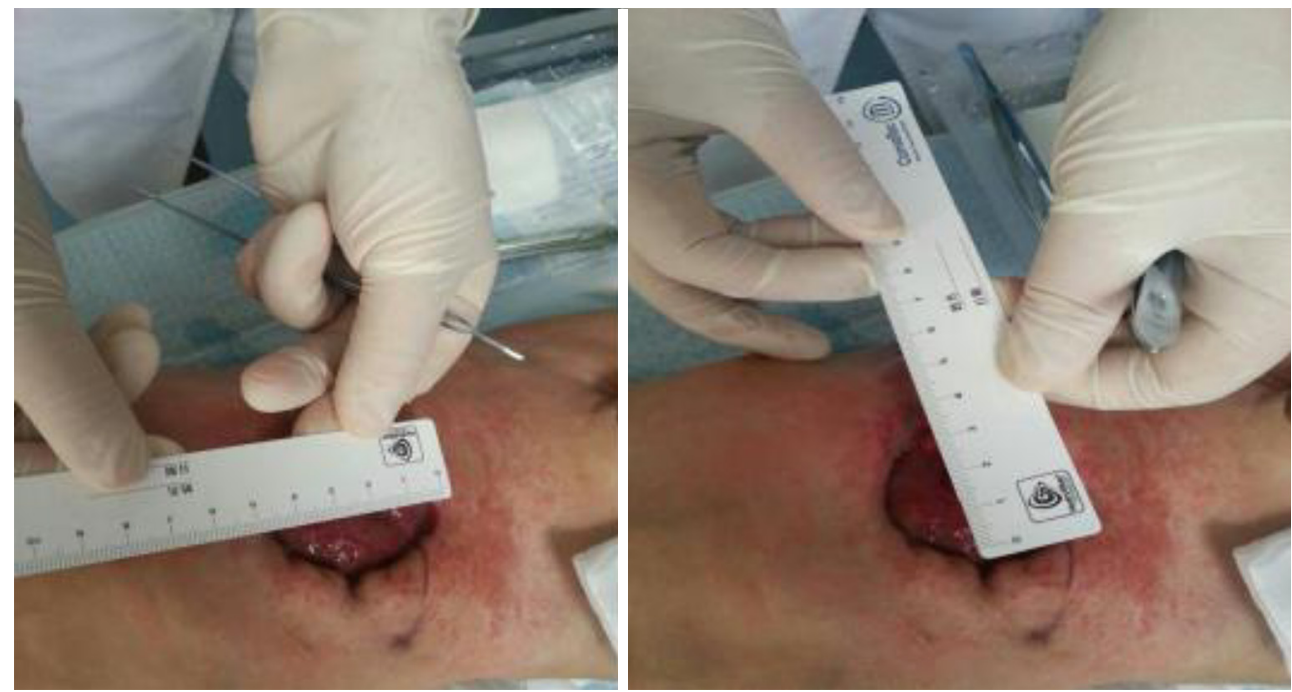

Figure 8 The left-sided wound on September 5.

wound. The hydrofiber dressing with silver is a new wound dressing. It has the function of absorbing wound exudate and promoting autolysis of necrotic tissue by hydrophilic fiber. It also has an anti-infective effect of silver ions.

In addition to broad-spectrum antibacterial effect, it can absorb exudate 4-5 times the weight of 6 layers of gauze and form a gel, which helps to keep the wound moist, promote the autolysis of necrotic tissue, and promote the growth of granulation tissue (12). The wound base was filled with hydrofiber silver dressing, and then the wound was filled with gauze until it was even with the surrounding skin: however, the stoma needed to remain visible. The outermost layer was covered with DuoDearm ${ }^{\mathrm{TM}}$ extra thin hydrocolloid dressings, which facilitate the sticking of the stoma bag and created a micro-environment of heat preservation and moisture retention. Again, the stoma remained visible. The gap between the stoma and the hydrocolloid was filled with a leak-proof paste, so as to prevent liquid stool from penetrating into the wound and causing contamination. Conva Tec ${ }^{\mathrm{TM}}$ one-piece ostomy bag was selected, and the hole was cut out according to the size of stoma before it was placed over the stoma (Figure 9).

Granulation tissue growth phase: after the wound infection was controlled, the wound exudate was reduced to a moderate amount. Alginate dressing was used to fill the wound base. Gauzes were used to fill the wound until they were even with the skin around the wound. Ultra-thin hydrocolloid was applied externally, followed by the sticking 
of the ConvaTec one-piece ostomy bag over the stoma.

Outcomes: the wound was filled with hydrofiber silver dressing, combined with intravenous administration of drugs. The wound dressing was changed daily. After 9 days, the infection was controlled, the body temperature returned to normal, and the amount of exudate was reduced to a moderate amount. Alginate dressing was used instead, and the wound dressing was changed every 2-3 days. After 8 days, the granulation tissue began to grow, and the exudate further decreased to a small amount. The wound surface shrank further (Figures 10,11).

A second surgery (intestinal perforation repair and ileostomy) was performed on September 6, and the patient was discharged on September 20 (Figure 12).

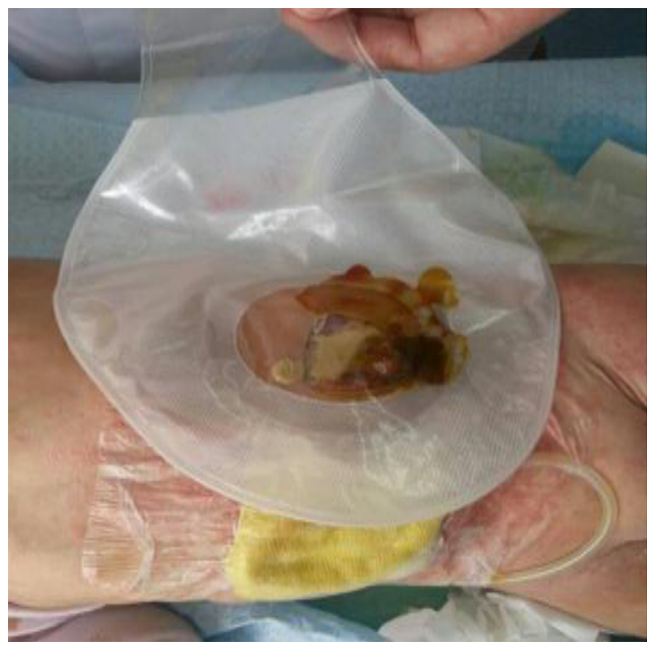

Figure 9 Sticking of the ConvaTec one-piece ostomy bag over the right-sided stoma.

\section{Psychological nursing}

The child was discharged early after the first ostomy due to economic reasons. Even worse, since his parents lacked the knowledge on home nursing, the wound infection gradually worsened. After the child was re-admitted, the enterostomal therapist actively communicated with the child's parents, listened to their complaints, explained the treatment protocols to them, and encouraged them to be involved in the postoperative nursing. The parents became more confident and relaxed after this exchange. For children, we take the initiative to learn about our children's home habits, try to maintain these habits while in hospital. Use encouraging, praiseful language with her parents, gradually get close to children and gain trust, then using nonverbal communication, like a hug, give her warmth. Invite other children to play with her.

\section{Lack of nursing knowledge}

Considering the family's educational level, when we explain the illness and treatment, we try to use simple and understandable language. Nursing instruction of stoma was given in the form of illustrations and pictures. Direct step by step.

\section{Discussion}

Closed negative-pressure drainage (CNPD) is a newly developed treatment for wounds. Since it has special requirements on its supplies, most of the devices for CNPD are commercially available in suits, and their prices are all higher than 800 yuan. With solid knowledge of the principles of CNPD, and the requirements of its
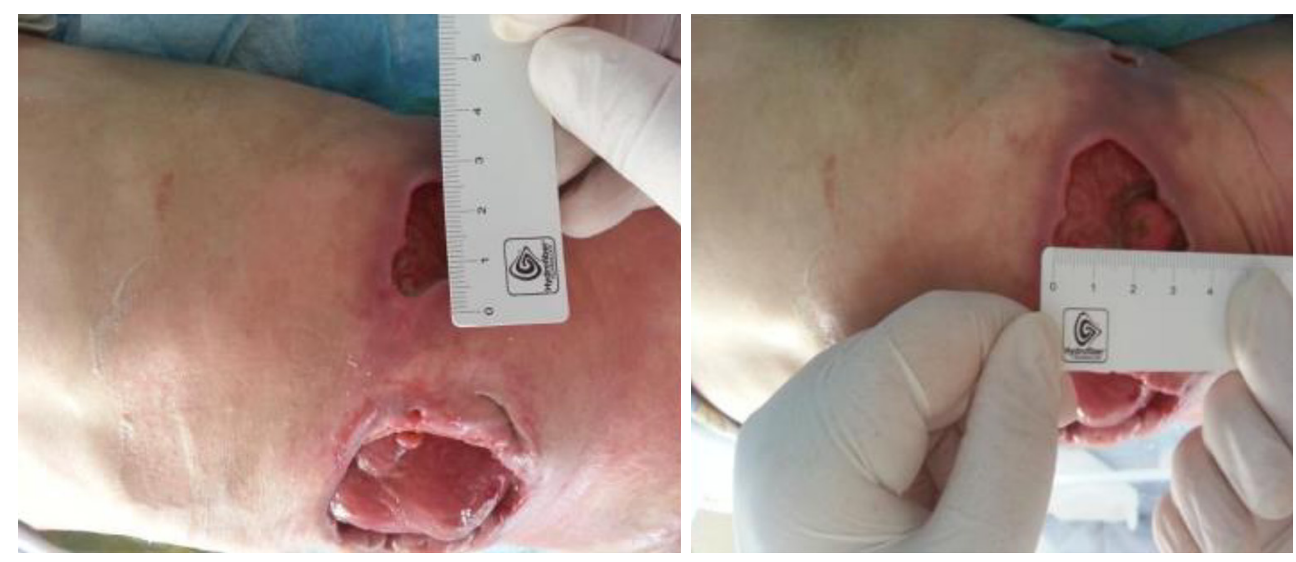

Figure 10 Right-sided wound on August 28. 

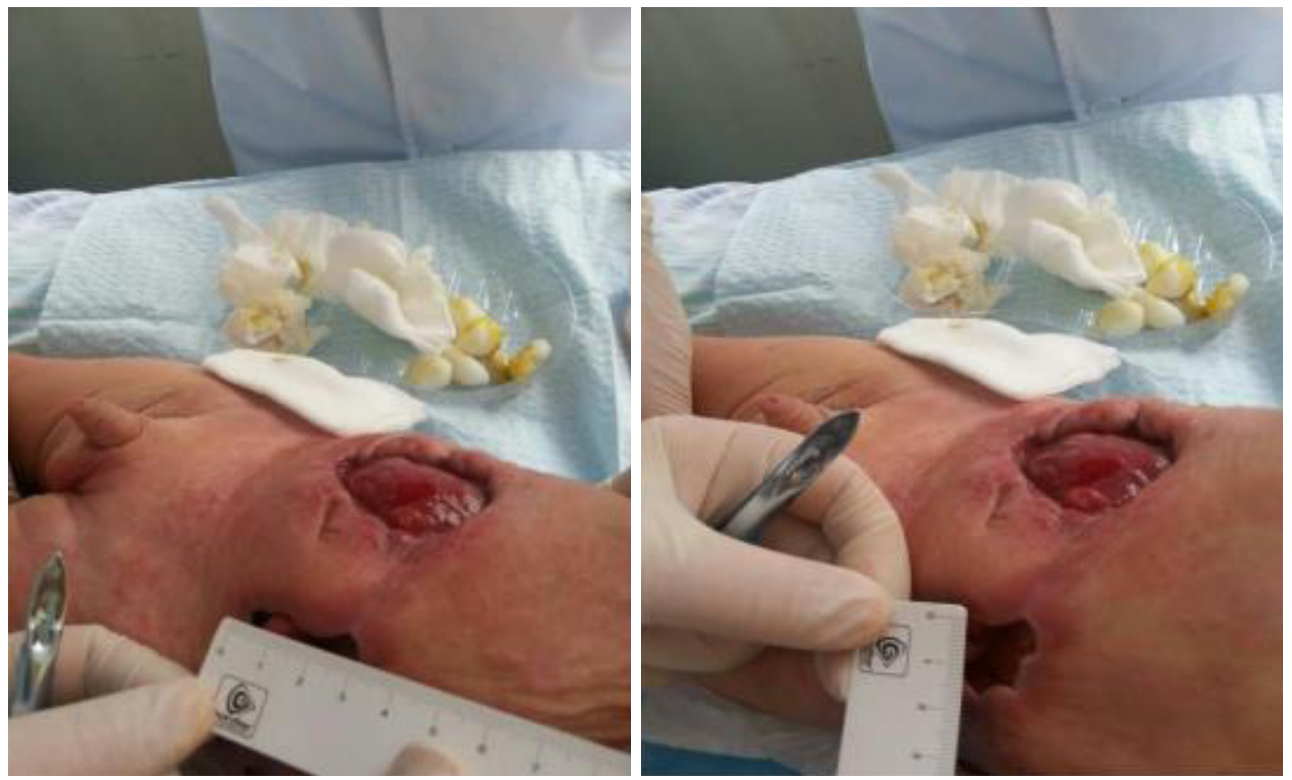

Figure 11 Right-sided wound on September 6.

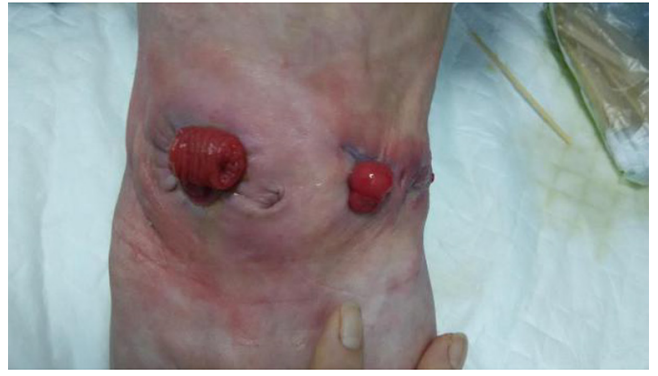

Figure 12 Wounds at discharge on September 20.

supplies, some enterostomal therapists have successfully used self-made CNPD devices using cheaper supplies to treat a variety of chronic wounds. For instance, $\mathrm{Li}$ et al. used their self-made simple CNPD device to treat 35 victims of Wenchuan earthquake in 2008, with satisfactory effectiveness. These self-made simple CNPD devices use cheap supplies, and thus can reduce the economic burden of patients; the supplies are easy to obtain and operate; thus, they are more acceptable for patients and their families in terms of price, portability, accessibility, and cooperation. However, these self-made CNPD devices often have difficulty in adjusting the negative pressure, which is not conducive to continuous and effective drainage. The enterostomal therapists must master the modern concepts and skills of wound care and be able to make a correct and comprehensive assessment of wounds. Also, they should be skilled in choosing appropriate and effective modern wound dressings based on the wound phase and the therapeutic targets. In our current case, since there was a large amount of exudate at the wounds, a hydrofiber silver dressing that absorbs much exudate and resists infection was selected during the infection phase. When the amount of exudate decreased, an alginate dressing that absorbs a small to moderate amount of exudate was selected to promote the growth of granulation tissue. According to the theory of wound bed preparation, the concept of wet wound healing is applied throughout wound care. A moist environment can promote local circulation and perfusion, lead to rapid multiplication of grow-promoting factors, stimulate the regeneration of local tissues, and accelerate the healing of wounds.

Different from adults, young children rely on their families to take care of their stomas after discharge (2). Therefore, psychological care and education on nursing skills should be offered to the family members of the children, so as to improve the postoperative outcomes of these children and increase the success rate of the second surgery. The enterostomal therapists should offer timely health and nursing education to the children's families.

For such cases, I suggest, ostomy therapists must fully grasp modern wet healing theory, Rational use of modern wound dressing, proper application of negative pressure drainage technique, treatment of local wounds and stoma problems, other aspects also need to be comprehensively 
assessed and addressed, for example, psychology, nutrition. Implementing holistic care.

\section{Acknowledgments}

Funding: None.

\section{Footnote}

Reporting Checklist: The author has completed the CARE reporting checklist. Available at http://dx.doi.org/10.21037/ apm-20-1189

Conflicts of Interest: The author has completed the ICMJE uniform disclosure form (available at http://dx.doi. org/10.21037/apm-20-1189). The author has no conflicts of interest to declare.

Ethical Statement: The author is accountable for all aspects of the work in ensuring that questions related to the accuracy or integrity of any part of the work are appropriately investigated and resolved. All procedures performed in studies involving human participants were in accordance with the ethical standards of the institutional and/or national research committee(s) and with the Helsinki Declaration (as revised in 2013). Written informed consent was obtained from the patient for publication of this manuscript and any accompanying images.

Open Access Statement: This is an Open Access article distributed in accordance with the Creative Commons Attribution-NonCommercial-NoDerivs 4.0 International License (CC BY-NC-ND 4.0), which permits the noncommercial replication and distribution of the article with the strict proviso that no changes or edits are made and the original work is properly cited (including links to both the formal publication through the relevant DOI and the license). See: https://creativecommons.org/licenses/by-nc-nd/4.0/.

\section{References}

1. Liang YF, Lai WH. Cause analysis and nursing

Cite this article as: Li S. Nursing of a child with wound infection and bowel evisceration following ileostomy: a case report. Ann Palliat Med 2020;9(4):2367-2374. doi: 10.21037/ apm-20-1189 countermeasures of ostomy irritant dermatitis of children. Chin J Coloproctol 2017;37:67-9.

2. Chen J, Zhao J. Peristomal skin assessment in children with colostomy and the influencing factors. Journal of Nursing Science 2017;(10):36-7, 36-8.

3. Zhao Q. Nursing after enterostomy in pediatric patients. Frontiers of Medicine 2017;7:282.

4. Li X. Care of children with intestinal fistula after surgery. Journal of Nurses Training 2015;30:884-5.

5. Xue HR, Ma XN. Nursing of a case of abdominal surgical wound dehiscence complicated with bowel evisceration. Journal of Clinical Nursing 2015;5:324.

6. Huang MR, Peng LF, Li MY, et al. Nursing care of a patient with stoma retraction and peristomal deep wound infection. Chinese Journal of Nursing 2014;21:49-50.

7. Hu AL, Zheng MC, Li WJ. Modern Clinical Nursing Practice of Wound and Stoma. Beijing: Peking Union Medical College Press, Chapter X Nursing of surgical incision infection and fat liquefaction, Section I Nursing of surgical incision infection, 2010:87-94.

8. Hu AL, Zheng MC, Li WJ. Modern Clinical Nursing Practice of Wound and Stoma. Beijing: Peking Union Medical College Press, Chapter IV Wound assessment, Section 2 Local assessment, 2010;35:372.

9. Cheng PY, Zhou HM, Wang L. Experimental and clinical study on negative pressure suction combined with nanosilver dressing for promoting healing of infected incision (J). Chinese Journal of Infection Control 2017;16:931.

10. Ma JY, Gao H, Kang YL. Nursing of a patient with inguinal incision and lymphatic leakage after internal aortic dissection with a self-made closed negative-pressure drainage device. Chinese Journal of Practical Nursing 2015;31:269.

11. Hu AL, Zheng MC, Li WJ. Modern Clinical Nursing Practice of Wound and Stoma. Beijing: Peking Union Medical College Press, Chapter IV Wound assessment, Section 3 Wound measurement, 2010:39.

12. Hu AL, Zheng MC, Li WJ. Modern Clinical Nursing Practice of Wound and Stoma. Beijing: Peking Union Medical College Press, Chapter VII Types and characteristics of dressings, Section 2 New closed and semi-closed dressings, 2010:60. 